\title{
Empirical seismic vulnerability curve for mortality: case study of China
}

\author{
Shaohong Wu $\cdot$ Jing Jin $\cdot$ Tao Pan
}

Received: 9 October 2014/Accepted: 6 January 2015/Published online: 21 January 2015

(C) Springer Science+Business Media Dordrecht 2015

\begin{abstract}
Most seismic casualty estimations are based on the vulnerability of various categories of structure and facilities in the region concerned. These approaches require detailed inventory database of the structures and facilities in the region. In China, however, the data is not always available, especially for some underdeveloped regions. This motivates the development of empirical models that use historical casualty data for earthquakes and provide a country- or region-specific earthquake death rate as a function of ground shake. However, diminishing divergences in fitting method and obtaining higher accuracy are still a great challenge. Building on the findings of previous research, the present paper employs vulnerability curves to express the relation between seismic intensity and mortality. From data of the death rate by intensity, curves are established for the whole of China and western China. Some methodological improvements are also discussed. To validate the curves, data from four recent strong earthquakes occurred in western China are used, and the best curves for estimation are selected and compared with similar models. Results indicate that the established curves for western China give a better estimation for the four earthquakes and the logistic functions show higher accuracy. They can be used to clarify the magnitude of seismic deaths in western China when structure and facility data are unavailable. Uncertainties and the application of the models are also analyzed and discussed in the conclusion.
\end{abstract}

Keywords Earthquake $\cdot$ Mortality estimation - Vulnerability curve $\cdot$ Empirical model

S. Wu · J. Jin · T. Pan

Key Laboratory of Land Surface Pattern and Simulation, Institute of Geographical Sciences and Natural Resources Research, Chinese Academy of Sciences, Beijing 100101, China

J. Jin $(\bowtie)$

University of Chinese Academy of Sciences, Beijing, China

e-mail: jinj@mail.las.ac.cn 


\section{Introduction}

Earthquakes are major natural disasters that result in heavy casualties and property losses (Ma 1990; Alexander 1993; Chen and Shi 2007; Wong 2014). The United States Geological Survey (USGS) estimated that there are millions of earthquakes around the world each year (USGS 2013). Most earthquakes are of small magnitude or strike in remote oceans and thus cannot be felt by people. However, strong earthquakes that strike in densely populated areas result in losses of property and life.

China is an earthquake-prone country. Half of its territory is prone to earthquakes with seismic intensity ${ }^{1}$ of VII or higher; this area includes 23 provincial capitals and two-thirds of the nation's large cities with a population of more than one million inhabitants (CEA 2013). In the twentieth century, half of the deaths caused by earthquakes around the world were in China, and half of the deaths caused by natural disasters in China since 1950 were due to earthquakes (CEA 2013). In recent years, the Chinese mainland has been hit by a number of severe earthquakes, including the Wenchuan earthquake in 2008, the Yushu earthquake in 2010 and the Lushan and Dingxi earthquakes in 2013. These earthquakes had different degrees of property losses and casualties.

The estimation of risk in terms of seismic mortality has drawn much attention from the scientific community because of the severe loss of life in earthquake disasters. Disaster risk refers to the potential losses of life, health status, livelihoods, assets and service systems in a disaster (UNDP 2004), emphasizing possible events and possible losses (Blaikie et al. 1994; Li et al. 2012; Selva 2013).

Over the past 20 years, there have been important advances in seismic science and engineering relating to the probabilistic estimation of seismic hazards and early warning, but there are uncertainties regarding source initiation, rupture phenomena and the accuracy of the timing and magnitude of earthquake occurrence that seem difficult to overcome (Kossobokov 2013). Estimation of possible losses, such as seismic mortality, is another important aspect of risk assessment. When an earthquake strikes, a proper estimation of possible mortalities is necessary to understand the magnitude of expected seismic losses and to facilitate decision making in relief operations.

To effectively estimate mortality in the event of an earthquake, a number of models at local or regional levels have been established, with most being based on the vulnerability of various categories of structure and facilities in the region concerned (Okada 1992; Coburn et al. 1992; Weimin 2002; Cheng and Yang 1993; Yin 1995). These models are also widely used by governments in earthquake loss evaluation systems, such as the HAZUS system developed by the Federal Emergency Management Agency (FEMA) and the PAGER system developed by the USGS. However, these models require a detailed inventory database of structures and facilities, which is not always readily available in many regions of the world (Jaiswal et al. 2011). In China, for example, the gathering of relevant complex structural parameters is not easy for two reasons. (1) In the past several decades, the socioeconomic development of different regions in China has been uneven. The buildings in cities and rural areas thus differ greatly in structure and materials, and even buildings of the same material have different seismic resistance. (2) With rapid economic growth in China, buildings are reconstructed frequently, and data on buildings cannot be updated in a timeframe suitable for modeling.

1 In this paper, intensity data on Chinese earthquakes are based on the China Seismic Intensity Scale (CSIS), which classifies seismic impacts into $12^{\circ}$. 
Empirical models have been developed because of the lack of structure and facility data in some regions. These models use historical earthquake casualty data and provide a country- or region-specific earthquake death rate as a function of the ground shake. They need fewer parameters and can help responders understand the scale of disasters more quickly. There have been many studies in this field since the twentieth century (Jaiswal et al. 2011; Samardjieva and Oike 1992; Samardjleva and Badal 2002; Nichols and Beavers 2003). As a typical empirical model, Jaiswal et al.'s (2011) model was used within the PAGER system of the USGS. The model uses seismic intensity as a key parameter and employs a two-parameter lognormal cumulative distribution function to characterize the relationship between seismic intensity and mortality. Li et al. (2012) produced separate models for western and eastern China by modifying the parameters of Jaiswal et al.'s model. Chen et al. (1998) proposed a method of assessing seismic losses based on macroeconomic and social indicators and applied it around the world. Taking the same approach, Liu et al. (2006) established models based on seismic intensity and corresponding death rates and applied them at a regional level. Other studies established models based on maximum intensity and the total number of deaths (Xiao 1991; Liu et al. 2012; Liu and Lin 2012). However, differences in the fitting methods used and the accuracy achieved pose a great challenge.

The present paper employs vulnerability curves to express the relation between seismic intensity and mortality. Data of the death rate by intensity are collected for 157 earthquakes between 1989 and 2004 in China and grouped by region. Curves are established using different regression methods and validated using data for the latest four severe earthquakes that struck China. The best three curves in the estimation are finally selected and compared with similar models. Results indicate that the curves established in this paper provide improved estimations of death rates and can feasibly be used to clarify the magnitude of seismic deaths in western China when structure and facility data are unavailable.

\section{Methods and data}

\subsection{Methods}

Ground-shake parameters mainly include the earthquake magnitude, seismic intensity and spectral acceleration. Seismic intensity is always taken as a main parameter because it has been demonstrated to have a strong association with the death rate (Liu et al. 2011) and intensity maps can be generated within several minutes of an earthquake through rapid estimations of ground motion (David et al. 2006, 1999; Lind et al. 1996). Maximum intensity at the epicenter and the total death rate are often used in empirical models (Chan et al. 1998; Liu et al. 2012; Liu and Lin 2012). However, it should be noted that the severity of an earthquake in most affected areas is not as high as that in the epicentral area, and damage is therefore less.

The paper thus considers such differences and retraces the death rate according to the distribution of intensity, taking the "death rate by intensity" as a key parameter which can be defined as the ratio of the deaths to the population of affected areas with the same intensity. The equation is:

$$
\mathrm{DRI}_{i}=\mathrm{DI}_{i} / \mathrm{PI}_{i}
$$

where $\mathrm{DRI}_{i}$ is the death rates in intensity $i, \mathrm{DI}_{i}$ is the deaths in intensity $i$, and PI is the population of the affected areas affected by the intensity $i, i=1,2,3,4,5,6, \ldots, 12$. By 
using regression methods, functional relationship between seismic intensity $(i)$ and the death rate by intensity $\left(\mathrm{DRI}_{i}\right)$ can be established, which is the vulnerability curve for mortality:

$$
\mathrm{DRI}_{i}=\mathrm{f}(i)
$$

When earthquake strikes, if we can approximately know the number of population by intensity $\left(\mathrm{PI}_{i}\right)$, the total death (TD) can be estimated as follows:

$$
\mathrm{TD}=\sum_{1}^{i}\left(\mathrm{DRI}_{i} \times \mathrm{PI}_{i}\right)
$$

Considering death rate divergence at same intensity, this study established curves based on "observed death rate" and "mean death rate" separately. Mean death rate is the mean value of observed death at same intensity. Differences in curve fitting are also compared.

In addition, China is a country of vast territory, where the geological structures, seismic zones and socioeconomic development differ markedly among regions. Such differences are distinct between western and eastern China. Moreover, earthquakes frequently strike western China. To improve the accuracy and applicability of the model, vulnerability curves both for the nation and for western regions are established. The western regions cover Yunnan Province, Sichuan Province, Gansu Province, Qinghai Province, the Xizang (Tibet) Autonomous Region and the Xinjiang Uygur Autonomous Region. These regions are divided into two groups, namely western region I (comprising Yunnan, Sichuan, Gansu and Xinjiang) and western region II (comprising Qinghai and Xizang) according to natural and socioeconomic differences.

\subsection{Data}

The data of death rate by intensity are mainly taken from Liu (2006), who collected detailed data for 157 earthquakes that struck Mainland China from 1989 to 2004, including the distribution of intensity, fatalities by intensity and corresponding population. The data on fatalities by CSIS intensity are a collection of official publications based on on-site recording and loss assessment. The number of population within areas of same intensity is computed in geographical information system (GIS) environment by using seismic intensity map and administrative unit map.

Taking the 1996 Lijiang earthquake data for example, the earthquake totally claimed 309 lives and the epicentral intensity is IX. Table 1 gives the area, population and deaths by intensity in the earthquake. The area of intensity IX is about $1,393.91 \mathrm{~km}^{2}$; the population and deaths in this area are 61,250 and 158. Then, the death rates by intensity (DRI)

Table 1 Catalog of data (taking the 1996 Lijiang earthquake as an example)

\begin{tabular}{lccll}
\hline $\begin{array}{l}\text { CSIS } \\
\text { intensity }(i)\end{array}$ & Areas/km ${ }^{2}$ & $\begin{array}{l}\text { Population by intensity } \\
(\text { PI) (persons) }\end{array}$ & $\begin{array}{l}\text { Deaths by intensity } \\
(\text { DI) }(\text { persons) }\end{array}$ & $\begin{array}{l}\text { Death rates by } \\
\text { intensity }(\%)(D R I)\end{array}$ \\
\hline IX & $1,393.91$ & 61,250 & 158 & 2.58 \\
VIII & $2,243.07$ & 97,390 & 76 & $7.80 \times 10^{-2}$ \\
VII & $4,179.26$ & 192,860 & 52 & $2.70 \times 10^{-2}$ \\
VI & $10,591.10$ & 498,980 & 23 & $4.61 \times 10^{-3}$ \\
\hline
\end{tabular}


can be calculated by Eq. (1), and Fig. 1 shows the scatter plot of actual death rates by intensity in Mainland China, central and eastern China and western China.

To validate the vulnerability curves derived in this paper, data on the dead or missing for four strong earthquakes that struck western China in recent years were collected from official publications (Zheng et al. 2010, 2011; SBSP 2013; SBGP 2013). The four earthquakes were the Wenchuan earthquake (May 12, 2008), Yushu earthquake (April 14, 2010), Lushan earthquake (April 12, 2013) and Dingxi earthquake (July 22, 2013). Table 2 shows the maximum intensity and total deaths in the earthquakes, missing persons are also taken into account.

The number of population by CSIS intensity (PI) in the four earthquakes was collected from the relevant studies (Xu et al. 2008; Fan 2010; Yu 2010) (Table 3).

\section{Establishment of seismic vulnerability curves}

A vulnerability curve describes the functional relationship between the intensity of the hazard and the loss caused (Shi 2010); in this paper, it describes the functional relationship between seismic intensity and the death rate by intensity. The vulnerability curve for mortality may rise with intensity in three stages, i.e., the curve initially rises slowly, then rapidly, and finally slowly again while approaching a peak level (where the peak death rate is 1 in this paper). Theoretically, as shown in Fig. 2, weak hazards (weak earthquakes) cause no death and are seldom taken into account. Meanwhile, there are almost no records of extreme hazards having almost $100 \%$ death rates since they rarely occur. Therefore, the middle part of the curve is mainly taken for fitting.

In this paper, different functions are applied for fitting. These functions can be categorized into three groups by shape. Type 1 comprises quadratic and cubic functions, type 2 comprises linear, logarithmic and reciprocal functions, and type 3 comprises composite, power, growth and exponential functions and $\mathrm{S}$ curves and logistic curves (Fig. 3, based on national data). The first two categories of functions have negative values in the fitting range and are not suitable. The significance level of type 3 curves is lower than 0.05 , and the composite function overlaps with growth and exponential functions. Therefore, composite and power functions and $S$ curves and logistic curves are used for fitting; the composite function can be replaced by a growth or exponential function. Such functions require there
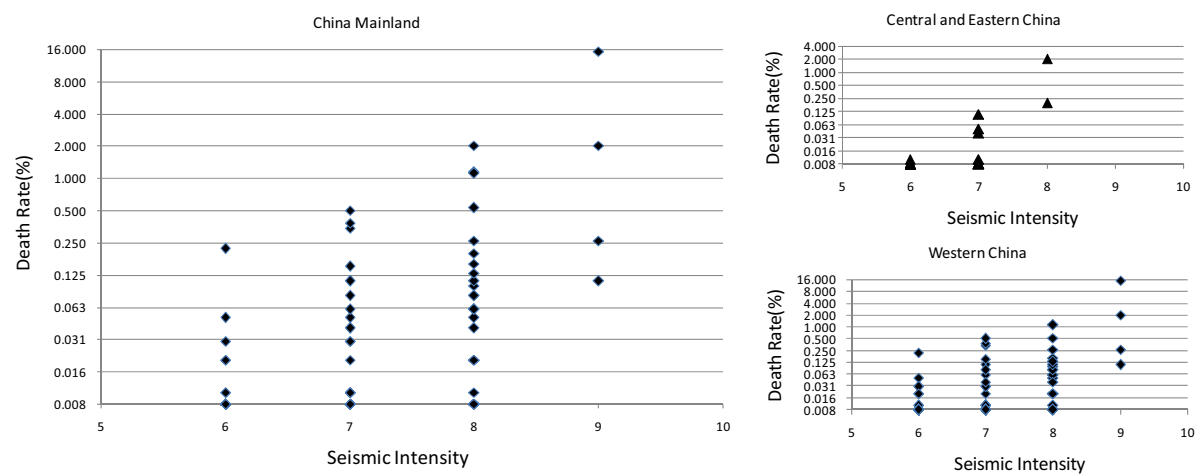

Fig. 1 Observed death rates by intensity 
Table 2 Total deaths in four earthquakes

\begin{tabular}{llc}
\hline Cases & Maximum intensity & Total deaths (persons) \\
\hline Wenchuan earthquake & XI & 87,150 \\
Yushu earthquake & IX & 2,968 \\
Lushan earthquake & IX & 217 \\
Dingxi earthquake & VIII & 95
\end{tabular}

Table 3 Population by CSIS intensity (PI) in the four earthquakes (persons)

\begin{tabular}{lrrrrrr}
\hline CSIS intensity cases & \multicolumn{1}{l}{ VI } & \multicolumn{1}{l}{ VII } & \multicolumn{1}{l}{ VIII } & \multicolumn{1}{l}{ IX } & X & XI \\
\hline Wenchuan earthquake & $71,100,600$ & $19,696,400$ & $4,327,300$ & 913,500 & 233,900 & 189,400 \\
Yushu earthquake & 197,441 & 54,997 & 59,483 & 16,200 & - & - \\
Lushan earthquake & $1,093,600$ & 544,900 & 153,000 & 61,800 & - & - \\
Dingxi earthquake & 915,000 & 525,000 & 108,000 & - & - & - \\
\hline
\end{tabular}

Fig. 2 Theoretical model of the vulnerability curve for mortality

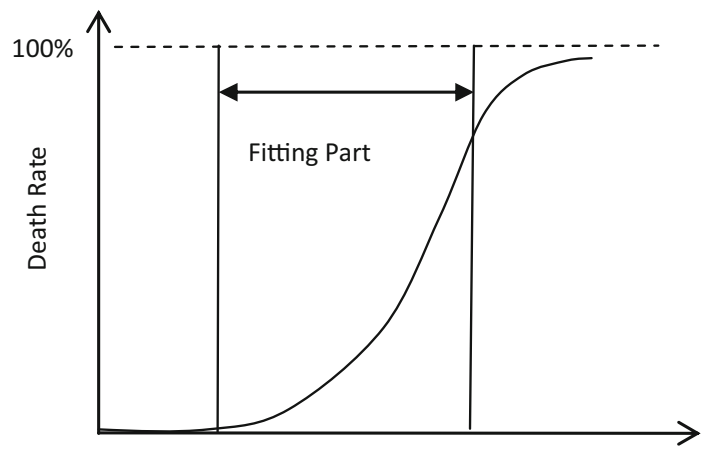

Seismic Intensity

to be no "zero-death" values (i.e., the Y-axis value should not be zero), which means zerodeath cases should be excluded. The data set has 78 cases meeting this requirement.

\subsection{Vulnerability curves based on national data}

The paper fit the vulnerability curves based on "observed death rate" and "mean death rate" separately (Fig. 4). According to the regression equations, estimated death rates in each intensity are calculated; Table 4 shows the equations and the estimated death rates when intensity is from VI to XI.

\subsection{Vulnerability curves for western China}

For national data, the standard deviation of death rate shows large divergence at same intensity and increases substantially with intensity. When intensity is VI, the standard deviation of death rate data is 0.044 , and when intensity reaches IX, the standard deviation exceeds 7 (Table 5). To improve the accuracy and applicability of the model, the paper 


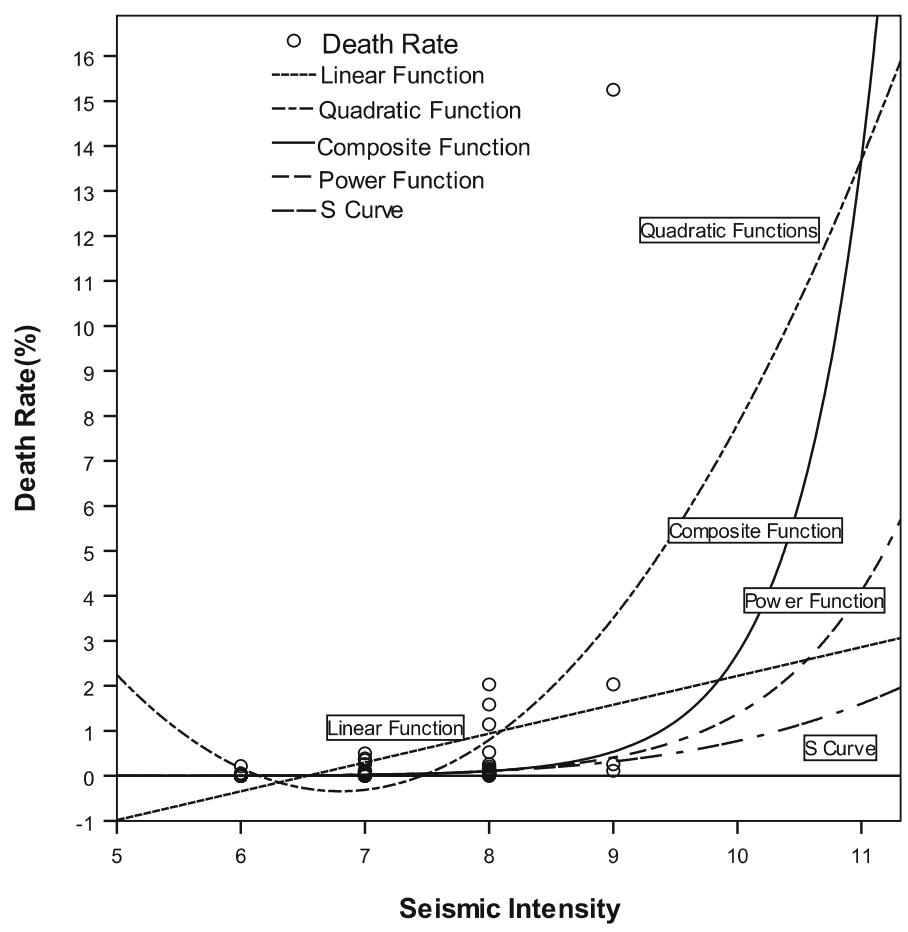

Fig. 3 Fitting results of different functions (national). Note Cubic and quadratic functions have similar curves. The linear function overlaps considerably with logarithmic and reciprocal functions. There are also overlaps between composite, growth and exponential functions and the logistic curve. For easy interpretation, only five curves are shown in the figure: the composite function, quadratic function, power function, $\mathrm{S}$ curve and linear function
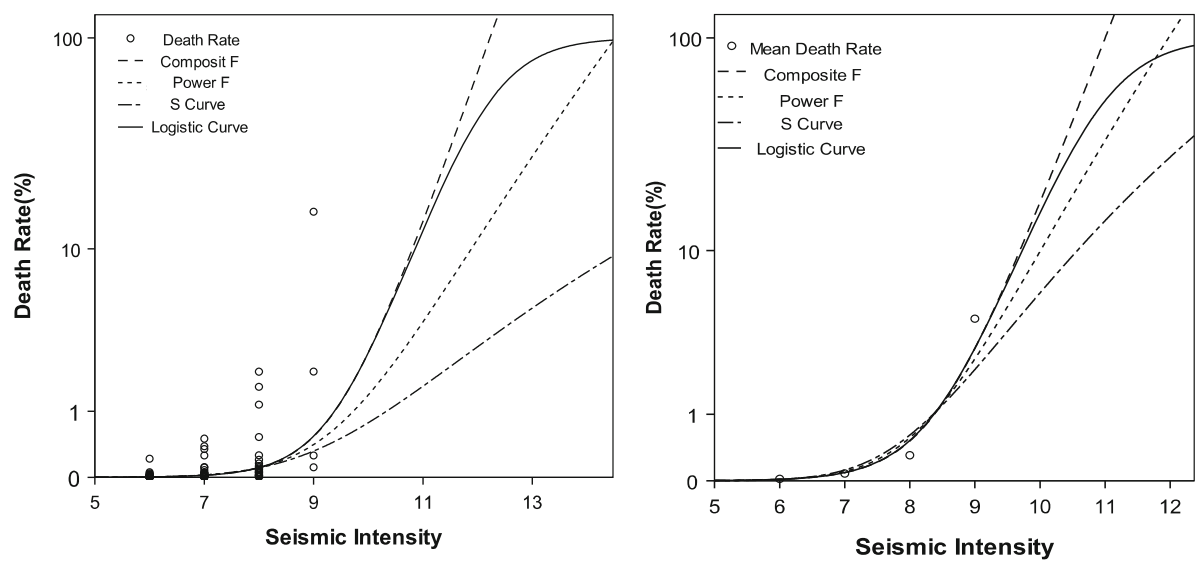

Fig. 4 Four types of vulnerability curves based on national data. (The Y axis is the observed death rate in the left figure and the mean death rate in the right figure) 


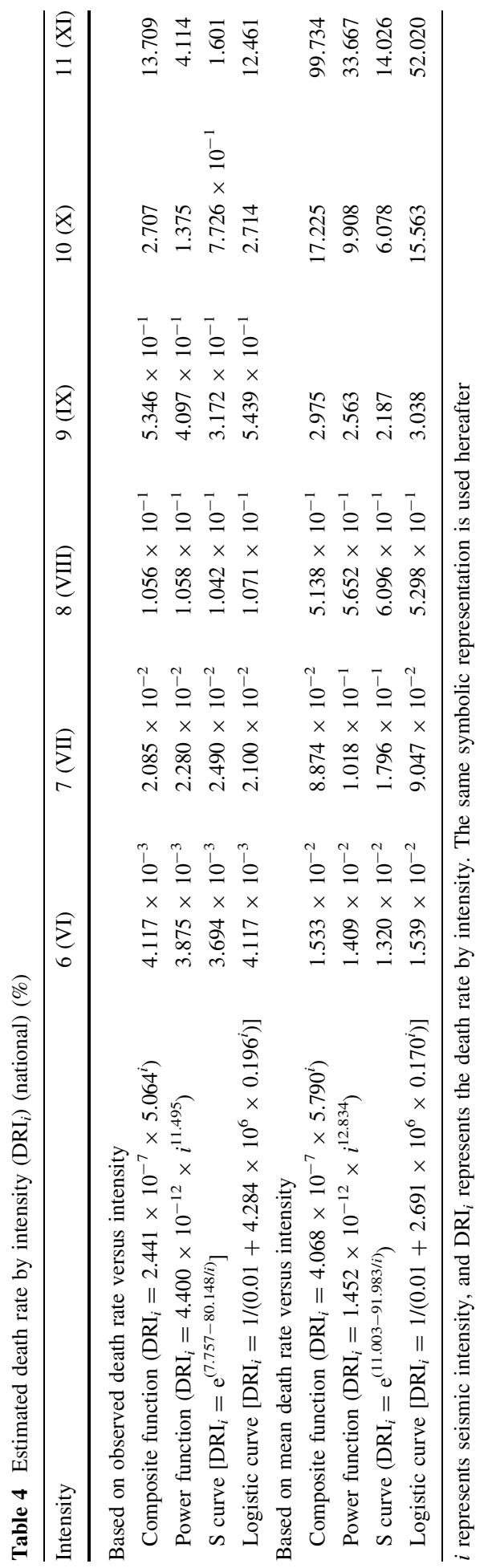


Table 5 Data and standard deviation at different intensities (western region I vs. national)

\begin{tabular}{|c|c|c|c|c|c|c|c|c|}
\hline & \multicolumn{2}{|l|}{ VI } & \multicolumn{2}{|l|}{ VII } & \multicolumn{2}{|l|}{ VIII } & \multicolumn{2}{|l|}{ IX } \\
\hline & $\begin{array}{l}\text { Sample } \\
\text { size }\end{array}$ & $\begin{array}{l}\text { Standard } \\
\text { deviation }\end{array}$ & $\begin{array}{l}\text { Sample } \\
\text { size }\end{array}$ & $\begin{array}{l}\text { Standard } \\
\text { deviation }\end{array}$ & $\begin{array}{l}\text { Sample } \\
\text { size }\end{array}$ & $\begin{array}{l}\text { Standard } \\
\text { deviation }\end{array}$ & $\begin{array}{l}\text { Sample } \\
\text { size }\end{array}$ & $\begin{array}{l}\text { Standard } \\
\text { deviation }\end{array}$ \\
\hline Nationwide & 23 & 0.044 & 27 & 0.130 & 21 & 0.551 & 4 & 7.277 \\
\hline $\begin{array}{l}\text { Western } \\
\text { region I }\end{array}$ & 17 & 0.003 & 21 & 0.008 & 17 & 0.275 & 3 & 1.070 \\
\hline
\end{tabular}

establishes vulnerability curves for west regions. West regions are also frequently stricken by earthquakes these years.

Considering natural and socioeconomic differences, this work divides western China into two parts: western region (I) and western region (II). Take the death rate data of western region (I) for instance, when intensity is VI, the data's standard deviation is 0.003 and when intensity reaches IX, the standard deviation is 1.070 (Table 5). The standard deviation for "western region (I)" is lower than that for the "National" thus help the improvement in the curves' accuracy and applicability. Since there are no recent seismic cases available for validation in central and eastern regions, these regions are not discussed further.

\subsubsection{Western region (I)}

The western region of China comprises 12 provinces, municipalities and autonomous regions. These areas are underdeveloped and differ greatly from central and eastern regions in terms of socioeconomic development. Since the validation data are mainly for Sichuan, Gansu, Yunnan, Qinghai, Xinjiang and Xizang, western region (I) in this study mainly refers to Sichuan, Gansu, Yunnan and Xinjiang. Qinghai and Xizang are discussed separately for their special natural and socioeconomic backgrounds. Figure 5 shows vulnerability curves for mortality in western region (I). According to the regression equations, estimated death rates in each intensity are calculated; Table 6 shows the equations and the estimated death rates when intensity is from VI to XI.

\subsubsection{Western region (II)}

Most of Qinghai and Xizang are within the seismic zone of the Qinghai-Xizang Plateau. There is frequent seismic activity in this zone, but in most cases, there are fewer deaths owing to the low population density. However, when earthquakes strike in counties with relatively dense population, the death rate is somewhat high because of improperly designed or unreinforced buildings, vulnerable lifelines and infrastructure and the severe environment of plateaus (Liu et al. 2010). Figure 6 shows the vulnerability curves for mortality in the case of Qinghai and Xizang. According to the regression equations, estimated death rates in each intensity are calculated; Table 7 shows the equations and the estimated death rates when intensity is from VI to XI.

\section{Validation of vulnerability curves}

All four severe earthquakes mentioned in Sect. 2 struck western region (I) and western region (II) and can thus be used to validate the established curves. Meanwhile, three similar curves established by other researchers are selected for comparison. 

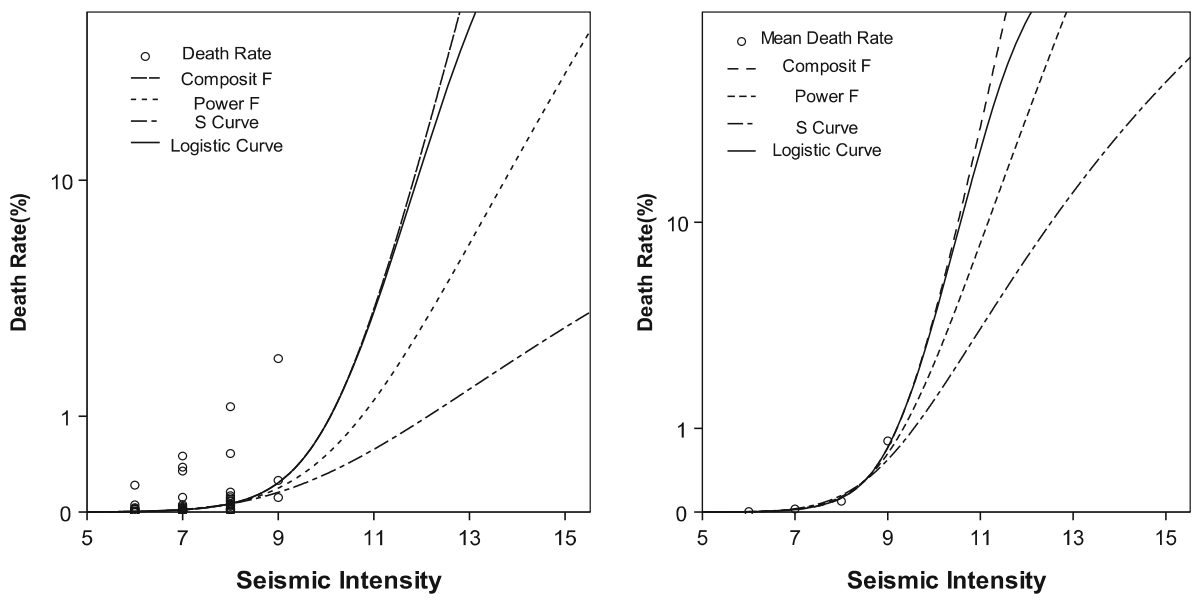

Fig. 5 Four types of vulnerability curves for western region I. (The Y axis is the observed death rate in the left figure and the mean death rate in the right figure)

\subsection{Evaluation with earthquake data}

The total deaths (TD) of the four earthquakes are estimated from Eq. (3), where the death rates by intensity $\left(\mathrm{DRI}_{i}\right)$ are the estimation results of different curves in Sect. 3 (Tables 4 , 6, 7); populations by intensity (PI) are from Table 3. Because Wenchuan, Lushan and Dingxi earthquakes occurred in western region (I), the national curves and west region (I) curves are used for estimation. Yushu earthquake occurred in western region (II); the national curves and west region (II) curves are used for estimation. The results are shown in Table 8 and reveal the following:

1. There are definite differences in seismic mortalities among regions, and the curve fitting using regional data provides better results. Vulnerability to earthquakes varies among regions in China, and the vulnerability curves established by data for western regions are more suitable for estimating losses in earthquakes striking those regions.

2. The curves based on the observed death rate and mean death rate have different characteristics, especially for western region (I). When the maximum intensity is no higher than 9, such as for the earthquakes in Lushan and Dingxi, the curves based on the observed death rate provide a better estimation than the curves based on the mean death rate. When the maximum intensity exceeds 9, such as for the Wenchuan earthquake, the curves based on the mean death rate give a better estimation than the curves based on the observed death rate.

3. The estimation of the logistic curve is closest to the actual losses. The three-stage growth and the feature of convergence echo the theoretical model of the vulnerability curve. Therefore, the following curves are selected in this study to estimate mortality due to earthquakes in western China.

Western region (I):

when maximum intensity $\leq 9$

$$
\mathrm{DRI}_{i}=1 /\left(0.01+4.186 \times 10^{7} \times 0.165^{i}\right)
$$




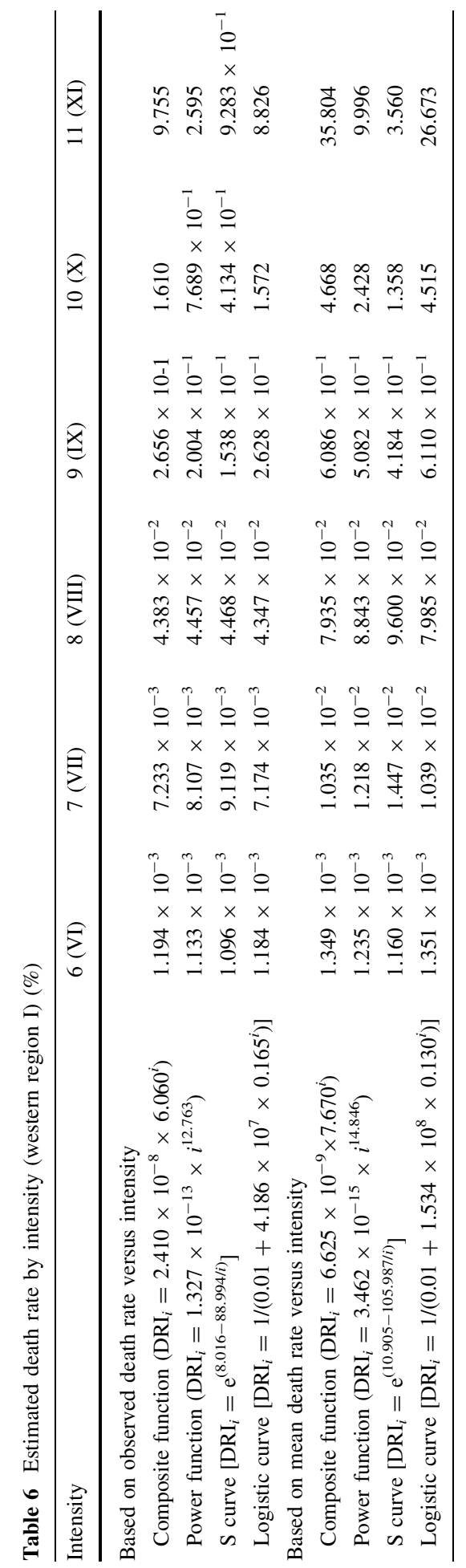



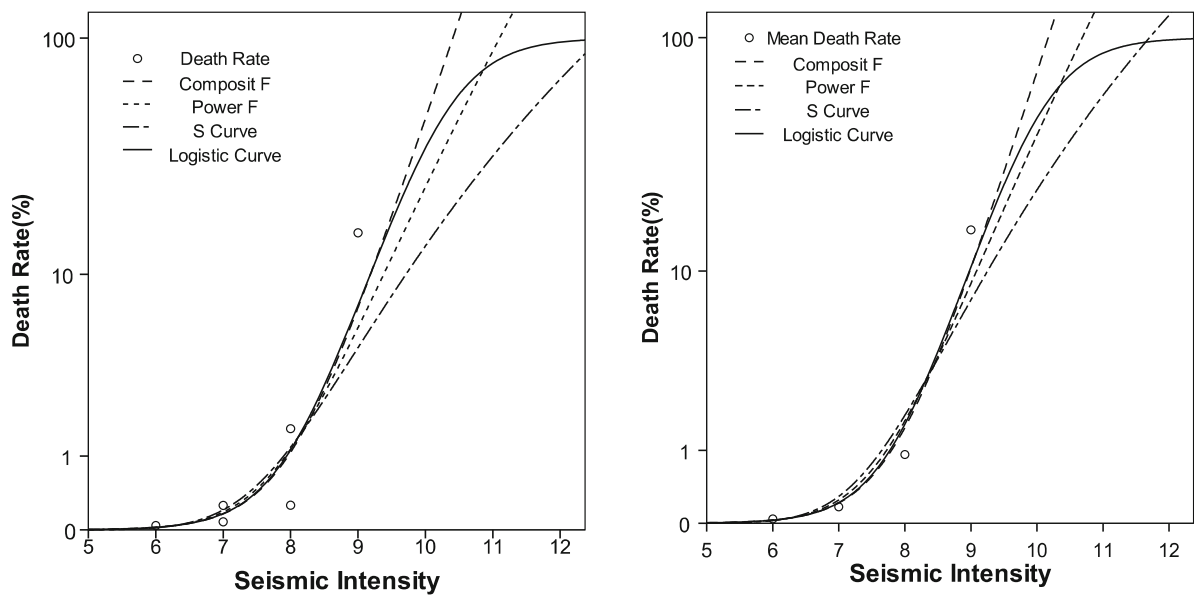

Fig. 6 Four types of vulnerability curve for western region II. (The Y axis is the observed death rate in the left figure and the mean death rate in the right figure)

when maximum intensity $>9$

$$
\mathrm{DRI}_{i}=1 /\left(0.01+1.534 \times 10^{8} \times 0.130^{i}\right)
$$

Western region (II):

$$
\mathrm{DRI}_{i}=1 /\left(0.01+5.263 \times 10^{6} \times 0.136^{i}\right)
$$

\subsection{Comparison of similar curves}

\subsubsection{Three models are selected for comparison}

Curve 1 is a global empirical model used in the USGS PAGER system and is expressed by a two-parameter lognormal cumulative distribution function (Jaiswal et al. 2011). Using the model, Chinese scholars have produced curves for western and eastern China separately (Li et al. 2012).

$$
\begin{aligned}
& \text { For eastern regions: } \quad V(S)=\Phi\left[\frac{1}{0.1231} \ln \left(\frac{S}{11.2924}\right)\right] \\
& \text { For western regions: } \quad V(S)=\Phi\left[\frac{1}{0.1065} \ln \left(\frac{S}{11.4571}\right)\right]
\end{aligned}
$$

where $\Phi$ is the standard normal distribution function, and $S$ is seismic intensity.

Curve 2 is established from the death rate by intensity (Liu 2006) and is expressed by a power function where $R$ is the death rate and $I$ is seismic intensity. When the gross domestic product (GDP) per capita (at constant prices in 2000) in the affected area is no $<2,700$ yuan, Formula (9) is used. When the GDP per capita (at constant prices in 2,000) is $<2,700$ yuan, Formula (10) is used. 


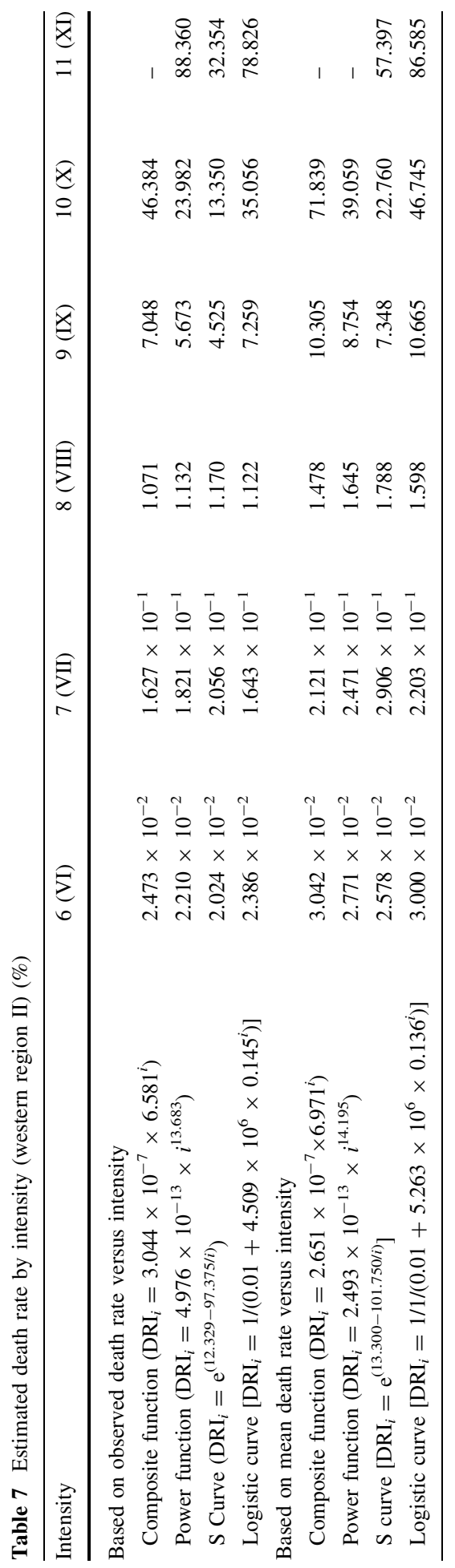


Table 8 Estimation of total deaths (TD) in four earthquakes using different curves. Values in bold are the estimations of the three selected curves, which are Eqs. (4)-(6)

\begin{tabular}{|c|c|c|c|c|}
\hline & Wenchuan earthquake & Yushu earthquake & Lushan earthquake & Dingxi earthquake \\
\hline \multicolumn{5}{|l|}{ National curves } \\
\hline \multicolumn{5}{|c|}{ Observed death rate versus intensity } \\
\hline Composite F & 48,781 & 169 & 650 & 261 \\
\hline Power F & 26,575 & 149 & 582 & 269 \\
\hline$S$ curve & 19,778 & 134 & 532 & 277 \\
\hline Logistic curve & 46,616 & 171 & 659 & 264 \\
\hline \multicolumn{5}{|c|}{ Mean death rate versus intensity } \\
\hline Composite F & 306,975 & 867 & 3,276 & 1,161 \\
\hline Power F & 164,884 & 835 & 3,158 & 1,274 \\
\hline$S$ curve & 119,763 & 808 & 3,072 & 1,398 \\
\hline Logistic curve & 214,372 & 887 & 3,350 & 1,188 \\
\hline \multicolumn{5}{|c|}{ Western region (I) curves } \\
\hline \multicolumn{5}{|c|}{ Observed death rate versus intensity } \\
\hline Composite F & 28,837 & - & 284 & 96 \\
\hline Power F & 12,875 & - & 249 & 101 \\
\hline$S$ curve & 8,638 & - & 225 & 106 \\
\hline Logistic curve & 26,930 & & 281 & 95 \\
\hline \multicolumn{5}{|c|}{ Mean death rate versus intensity } \\
\hline Composite F & 72,360 & - & 784 & 280 \\
\hline Power F & 40,204 & - & 766 & 307 \\
\hline S curve & 29,505 & - & 752 & 338 \\
\hline Logistic curve & 73,122 & & 571 & 153 \\
\hline \multicolumn{5}{|c|}{ Western region (II) curves } \\
\hline \multicolumn{5}{|c|}{ Observed death rate versus intensity } \\
\hline Composite F & - & 1,917 & - & - \\
\hline Power F & - & 1,736 & - & - \\
\hline$S$ curve & - & 1,582 & - & - \\
\hline Logistic curve & & 1,981 & & \\
\hline \multicolumn{5}{|c|}{ Mean death rate versus intensity } \\
\hline Composite F & - & 2,726 & - & - \\
\hline Power F & - & 2,587 & - & - \\
\hline$S$ curve & - & 2,465 & - & - \\
\hline Logistic curve & & 2,858 & & \\
\hline Actual death & 87,150 & 2,968 & 217 & 95 \\
\hline
\end{tabular}

$$
\begin{aligned}
& R=9 \times 10^{-15} I^{14.977} \\
& R=6 \times 10^{-11} I^{9.849}
\end{aligned}
$$

GDP per capita of 2,700 yuan is taken as a threshold in the selection of curves for different regions; this threshold was set to identify poverty-stricken counties in China in 2002. In 2008, however, the average per capita GDP of the 592 national-level poverty- 
stricken counties exceeded 8,771 yuan (Xie and Xu 2011), and few counties had a per capita GDP of $<2,700$ yuan. Therefore, Formula (9) is mainly used here for comparison.

Curve 3 is based on the maximum intensity and total death rate of 257 earthquakes that caused human losses in China between 1900 and 2009 (Liu et al. 2012). The curve is expressed by an exponential function, where $y$ is the death rate and $x$ is the maximum intensity.

$$
y=3 \times 10^{-5} e^{0.8185 x}
$$

The three curves are selected because they have important similarities and differences with the curves derived in this study. Curve 1 is similar in that it considers regional division. Curve 2 is similar in that it takes the death rate by intensity as a key parameter and is different in that it uses a single economic indicator (per capita GDP of 2,700 yuan) as the threshold. Curve 3 is different in that it takes the maximum intensity and total death rate as the main parameters.

Table 9 shows that the logistic curves established in this paper have a mean relative error of 0.12 in estimating deaths of the four earthquakes. The logistic curves have the smallest mean relative error among the four curves and can provide a better estimation.

\section{Discussion and conclusion}

Using data of the death rate by CSIS intensity, seismic vulnerability curves for mortality in China were established at both national and regional levels. Additionally, seismic loss data were used to validate the curves. The following conclusions are drawn from the results obtained.

1. The relationship between seismic intensity and mortalities is nonlinear for earthquake disasters in China. A logistic curve better describes such a relationship.

2. There are definite differences in seismic mortalities among regions. Fitting with regional data provides better results. These results were confirmed using data for recent earthquakes.

3. The vulnerability curves derived from death rate data by intensity provide a better estimation than those derived from the total death rate and maximum intensity.

4. The curves established in this paper provide improved estimations of fatalities. The results also suggest that with incomplete loss data for earthquakes around the world, a

Table 9 Comparison of the four curves in deaths estimation (persons). Values in bold are the estimations and mean relative error of the logistic curves built in this study

\begin{tabular}{|c|c|c|c|c|c|}
\hline & $\begin{array}{l}\text { Wenchuan } \\
\text { earthquake }\end{array}$ & $\begin{array}{l}\text { Yushu } \\
\text { earthquake }\end{array}$ & $\begin{array}{l}\text { Lushan } \\
\text { earthquake }\end{array}$ & $\begin{array}{l}\text { Dingxi } \\
\text { earthquake }\end{array}$ & $\begin{array}{l}\text { Mean relative } \\
\text { error }^{\mathrm{a}}\end{array}$ \\
\hline Curve 1 & 104,967 & 217 & 1,310 & 42 & 1.68 \\
\hline Curve 2 & 127,441 & 495 & 2,411 & 578 & 4.12 \\
\hline Curve 3 & 676,819 & 3,326 & 15,453 & 10,836 & 190.16 \\
\hline $\begin{array}{l}\text { Logistic curves (in } \\
\text { this study) }\end{array}$ & 73,122 & 2,858 & 281 & 95 & 0.12 \\
\hline Actual death & 87,150 & 2,968 & 217 & 95 & - \\
\hline
\end{tabular}

${ }^{\text {a }}$ Relative error $=$ lestimated deaths - actual deathsl/actual deaths 
collection of detailed information, such as loss by intensity, is important not only to vulnerability studies but also to emergency rescue in the future.

5. Data on high-intensity events are limited because there are few severe earthquakes, which affects the curve stability. Curves might be improved using more data, especially data on high-intensity events in the future. It should also be noted that the uncertainties in intensity map estimation will result in uncertainties in rapid death estimation. A number of contributing factors affect the accuracy of a given intensity map (Lin et al. 2005), to quantify the intensity map uncertainties can also help the improvement of death estimation (David et al. 2006).

Earthquake-caused deaths are also affected by other multiple uncertain factors. The first factor is the specific time of the earthquake occurrence. The time determines the possibility of human activities and thus the extent of casualties. The second factor is the structure and materials of buildings, which are related to property losses and casualties directly or indirectly. The third factor is individual characteristics, including socioeconomic status (income, political power and prestige), gender, age, education and cultural background (Zebardast 2013; Gabriela and Lisa 2012). These individual characteristics are related to the reaction of people when facing disasters. It is still a great challenge to fully understand how these factors relate earthquakes to disasters, and the combination of so many factors surely leads to a high level of uncertainty.

Given the approximate nature of empirical models, the models are needed more in developing regions where little is known of the structural properties and seismic resistance of local building types (Spenc et al. 2011), and the models can also provide a useful benchmark for calibrating losses taking both hybrid and analytical approaches (Jaiswal et al. 2011). In future work, by collecting more data and improving interpretation, better vulnerability curves can be developed. New parameters such as the time of earthquake occurrence can also be considered in modifying the curves and improving stability.

Acknowledgments This study is supported by the National Science and Technology Support Program of China (Grant No. 2013BAK05B04). We greatly appreciate the anonymous reviewers for their insightful comments, which led to significant improvement in the manuscript.

\section{References}

Alexander D (1993) Natural disasters. Chapman and Hall, New York

Blaikie P, Cannon T, Davis I, Wisner B (1994) At risk: natural hazards, people's vulnerability, and disasters. Routledge, London

Chan LS, Chen Y, Chen Q, Chen L, Liu J, Dong W, Shan H (1998) Assessment of global seismic loss based on macroeconomic indicators. Nat Hazards 17:269-283

Chen Y, Shi PJ (2007) Natural disasters. Beijing Normal University Press, Beijing

Cheng JY, Yang Z (1993) Regression analysis of mortality and the ratio of collapsing houses by Tangshan earthquake. Seismol Geol 15(1):82-87

China Earthquake Administration (CEA) (2013) The earthquake science and technology development plan (2006-2020). http://www.cea.gov.cn/publish/dizhenj/121/151/20120203175339937253453/index. html. Accessed 10 Aug 2013

Coburn AW, Spence RJ, Pomonis A (1992) Factors determining human casualties mortality prediction in building collapse. In: The tenth world conference on earthquake engineering, vol 10, pp 5989-5994

David JW, Quitoriano V, Thomas HH (1999) TriNet "Shake Maps": rapid generation of peak ground motion and intensity maps for earthquake in Southern California. Earthq Spectra 15(3):537-555

David JW, Paul SE, Lin KW (2006) Challenges in rapid ground motion estimation for the prompt assessment of global urban earthquakes. Bull Earthq Res Inst Univ Tokyo 81(1):273-281 
Fan J (2010) Restruction of Yushu after earthquake: assessment on resources and environment capacity. Science Press, Beijing

Gabriela RN, Lisa GL (2012) Social vulnerability assessment for mitigation of local earthquake risk in Los Angeles County. Nat Hazards 65:1331-1359

Jaiswal KS, Wald DJ, Earle PS, Porter KA, Hearne M (2011) Earthquake casualty models within the USGS prompt assessment of global earthquakes for response (PAGER) system. In: Robin S, Emily S, Charles $\mathrm{S}$ (eds) Human casualties in earthquakes: progress in modelling and mitigation. Springer, New York

Kossobokov VG (2013) Earthquake prediction: 20 years of global experiment. Nat Hazards 69:1155-1177

Li KZ, Wu SH, Dai EF (2012a) Flood loss analysis and quantitative risk assessment in China. Nat Hazards 63:737-760

Li XJ, Jiang LX, Yang TQ (2012b) Estimation of casualty in strong earthquake using empirical regression method. Northwest Seismol J 34(1):44-49

Lin KW, David JW, Bruce W, Anthony FS (2005) Quantifying CISN shakemap uncertainty. SMIP05 seminar on utilization of strong-motion data, pp 37-50

Lind SG, Douglas SN, Douglas SD (1996) Real-time seismology at UC Berkeley: the rapid earthquake data integration project. Bull Seismol Soc Am 86(4):936-945

Liu JF (2006) The study on applicability of macroscopic indicator vulnerability to a small-scale region. Institute of Geophysics, China Earthquake Administration, Beijing

Liu JL, Lin JQ (2012) Study on assessment method for earthquake casualty based on epicentral intensity. J Nat Disasters 21(5):113-119

Liu JF, Shi PJ, Fan YD, Zhang KM (2010) Features and revelation of the April 142010 Yushu Earthquake disaster in Qinghai Province. J Beijing Norm Univ 46(5):630-633

Liu Y, Wu SH, Xu ZC, Dai EF (2011) Methodology for assessment and classification of natural disaster risk: a case study on seismic disaster in Shanxi Province. Geogr Res 32(2):195-208

Liu H, Xu ZC, Wu SH, Liu RG (2012) GIS-based analysis of earthquake disaster population risk in China. Prog Geogr 31(3):368-374

Ma ZJ (1990) Natural disasters and disaster reduction: 600 questions. Seismological Press, Beijing

Nichols JM, Beavers JE (2003) Development and calibration of an earthquake fatality function. Earthq Spectra 19(3):605-633

Okada S (1992) Indoor-zoning map on dwelling space safety during an earthquake. The tenth world conference on earthquake engineering 10: 6037-6042

Samardjieva E, Oike K (1992) Modeling the number of casualties from earthquake. J Nat Disaster Sci 14(1):17-28

Samardjleva E, Badal J (2002) Estimation of the expected number of casualties caused by strong earthquakes. Bull Seismol Soc Am 92(6):2310-2322

Seismological Bureau of Gansu Province (SBGP) (2013). About the 6.6 magnitude earthquake in Min and Zhang county. http://www.gssb.gov.cn/pub/work/2013/07/23/1374565684996.html. Accessed 10 Aug 2013

Seismological Bureau of Sichuan Province (SBSP) (2013). "4.20" Earthquake in Lushan has claimed 196 lives. http://www.eqsc.gov.cn/zt/ljysdzzt_2191/swqk/201304/t20130430_26130.html. Accessed 10 Aug 2013

Selva J (2013) Long-term multi-risk assessment: statistical treatment of interaction among risks. Nat Hazards 67:701-722

Shi PJ (2010) Atlas of natural disaster risk of China. Science Press, Beijing

Spenc R, So E, Jenkins S, Coburn A, Ruffle S (2011) A global earthquake building damage and casualty database. In: Robin S, Emily S, Charles S (eds) Human casualties in earthquakes: progress in modelling and mitigation. Springer, New York

UNDP Bureau for Crisis Prevention and Recovery (2004) Reducing disaster risk: a challenge for development-a global report. John S. Swift Co., New York

USGS (2013) Earthquake facts and statistics. http://earthquake.usgs.gov/earthquakes/eqarchives/year/ eqstats.php. Accessed 26 Aug 2013

Weimin D (2002) Earthquake models for catastrophe risk and their application to insurance. Earthq Eng Eng Vib 1(1):145-151

Wong IG (2014) How big, how bad, how often: are extreme events accounted for in modern seismic hazard analyses? Nat Hazards 72:1299-1309

Xiao GX (1991) Rapid assessment of disaster losses in post-earthquake. J Catastrophol 6(4):12-17

Xie HP, Xu JW (2011) Economic development patterns research for resource oriented counties in China. Research Press, Beijing

Xu GD, Fang WH, Shi PJ, Yuan Y (2008) The fast loss assessment of the Wenchuan earthquake. J Earthq Eng Eng Vib 28(6):74-83 
Yin ZQ (1995) Prediction method of earthquake disaster and loss. Seismological Press, Beijing

Yu SZ (2010) Investigations of damaged houses in Yushu earthquake. J Civil Archit Environ Eng 32(2):13-15

Zebardast E (2013) Constructing a social vulnerability index to earthquake hazards using a hybrid factor analysis and analytic network process (F'ANP) model. Nat Hazards 65:1331-1359

Zheng TY, Li Y, Hou JS, Mi HL (2010) Review on earthquake disaster loss in Chinese mainland in 2008. J Catastrophol 25(2):112-118

Zheng TY, Zhao P, Liu ZT (2011) Review on earthquake disaster loss in Chinese mainland in 2010. J Nat Disasters 20(4):107-113 